\title{
Consistency of the current global ocean observing systems from an Argo perspective
}

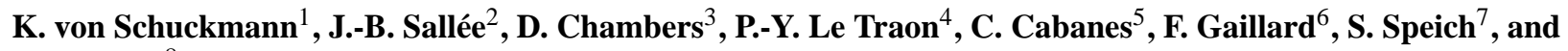 \\ M. Hamon $^{8}$ \\ ${ }^{1}$ Mediterranean Institute of Oceanography (MIO), Université de Toulon, Aix-Marseille Université, CNRS, IRD, \\ MIO UM 110, La Garde, France \\ ${ }^{2}$ Sorbonne Universités (Univ Paris 6)-IRD-CNRS-MNHN, LOCEAN, Paris, France and British Antarctic Survey, \\ Cambridge, UK \\ ${ }^{3}$ College of Marine Science, University of South Florida, St. Petersburg, Florida, USA \\ ${ }^{4}$ Mercator Ocean and Ifremer, Ramonville, St. Agne, France \\ ${ }^{5}$ CNRS, DT/INSU, Plouzané, France \\ ${ }^{6}$ Ifremer, Brest, France \\ ${ }^{7}$ UBO, Brest, France \\ ${ }^{8}$ Mercator Ocean, Ramonville, St. Anne, France
}

Correspondence to: K. von Schuckmann (karina.von-schuckmann@univ-tln.fr)

Received: 23 May 2013 - Published in Ocean Sci. Discuss.: 25 June 2013

Revised: 4 April 2014 - Accepted: 24 April 2014 - Published: 24 June 2014

\begin{abstract}
Variations in the world's ocean heat storage and its associated volume changes are a key factor to gauge global warming and to assess the earth's energy and sea level budget. Estimating global ocean heat content (GOHC) and global steric sea level (GSSL) with temperature/salinity data from the Argo network reveals a positive change of $0.5 \pm 0.1 \mathrm{~W} \mathrm{~m}^{-2}$ (applied to the surface area of the ocean) and $0.5 \pm 0.1 \mathrm{~mm}$ year $^{-1}$ during the years 2005 to 2012 , averaged between $60^{\circ} \mathrm{S}$ and $60^{\circ} \mathrm{N}$ and the $10-1500 \mathrm{~m}$ depth layer. In this study, we present an intercomparison of three global ocean observing systems: the Argo network, satellite gravimetry from GRACE and satellite altimetry. Their consistency is investigated from an Argo perspective at global and regional scales during the period 2005-2010. Although we can close the recent global ocean sea level budget within uncertainties, sampling inconsistencies need to be corrected for an accurate global budget due to systematic biases in GOHC and GSSL in the Tropical Ocean. Our findings show that the area around the Tropical Asian Archipelago (TAA) is important to closing the global sea level budget on interannual to decadal timescales, pointing out that the steric estimate from Argo is biased low, as the current mapping methods are insufficient to recover the steric signal in the TAA
\end{abstract}

region. Both the large regional variability and the uncertainties in the current observing system prevent us from extracting indirect information regarding deep-ocean changes. This emphasizes the importance of continuing sustained effort in measuring the deep ocean from ship platforms and by beginning a much needed automated deep-Argo network.

\section{Introduction}

Changes to the earth's climate system, either of natural or anthropogenic origin, can cause an imbalance of the earth's energy budget (Bindoff et al., 2007). Over the last decades, increased human activities have significantly impacted our climate, forcing a net flux positive imbalance of $\sim 0.5 \mathrm{~W} \mathrm{~m}^{-2}$ at the top of the atmosphere, which is responsible for global warming (Hansen et al., 2011; Loeb et al., 2012). It is estimated that more than $90 \%$ of the excess energy is absorbed in the ocean, while the rest goes into melting sea and land ice and heating the land surface and atmosphere (Hansen et al., 2011; Church et al., 2011; Cazenave and Llovel, 2010). To close both the energy and sea level budgets, one needs accurate estimations of all terms. Observations during the 
era of the international Argo program (Roemmich and the A. S. Team, 2009) have a high potential to deliver accurate data to be used for such analyses (Hansen et al., 2011; von Schuckmann et al., 2009), in particular for the estimation of global ocean heat content (GOHC) and global steric sea level (GSSL), referred to here as global ocean indicators (GOIs, von Schuckmann and Le Traon, 2011).

Nevertheless, uncertainties of the Argo ocean observing system, sampling issues, and systematic biases still causes significant spread among the more recent estimates of GOHC and GSSL (Abraham et al., 2013; von Schuckmann and Le Traon, 2011). In particular, the detection of systematic biases represents a significant challenge for the Argo community, as they are associated with a coherent signature over large areas and are difficult to identify with current regional quality control procedures. Moreover, this type of error has a potentially large impact on Argo GOI estimations (Willis et al., 2009; Barker et al., 2011). The comparison of Argo GOIs to other global ocean observing systems such as total sea level from altimetry, and ocean mass observations from satellite gravimetry via the global sea level budget (e.g., Willis et al., 2008; Leuliette and Willis, 2011) is not only a potential quality control method to identify systematic biases in the Argo observing system, but also to test the effect of Argo sampling issues on GOI estimations.

The method consisting in comparing Argo GOIs to other global ocean observing systems relies on two assumptions. First, it assumes that systematic errors (e.g., regional biases or drifts) in either satellite altimetry or gravimetry are negligibly small. Second, steric changes in the deep ocean below $1500 \mathrm{~m}$ depth are excluded. Previous studies have shown that the latter assumption is not strictly valid, as the importance of deep-ocean temperature changes for estimating decadal changes in earth's radiation balance has been noted (e.g., Palmer et al., 2011). In the last decade, about $30 \%$ of the ocean warming has occurred below $700 \mathrm{~m}$, contributing significantly to an acceleration of the warming trend (Balmaseda et al., 2013; Trenberth, 2010). Purkey and Johnson (2010) used repeat deep hydrographic sections to measure abyssal warming and estimate $0.15 \pm 0.10 \mathrm{~mm}_{\text {year }}{ }^{-1}$ sea level rise, and $0.10 \pm 0.06 \mathrm{~W} \mathrm{~m}^{-2}$ of warming (applied to the surface area of the earth) below the $2000 \mathrm{~m}$ sampling limit of Argo since the mid-1990s. Moreover, recent studies have shown that heat is sequestered into the deep ocean during decades of large ocean-atmosphere variability, like El Niño-Southern Oscillation (ENSO) variability. This clearly highlights the important role of interannual variability in sequestering heat from the surface layer into the deep ocean (Roemmich and Gilson, 2011; Meehl et al., 2011; Balmaseda et al., 2013). Hence, steric changes in the deep ocean below $1500 \mathrm{~m}$ depth are important to understand changes of the global sea level budget.

In this study we use the globally distributed Argo measurements to update decadal rates of GOHC and GSSL for the period 2005-2012. The Argo SSL time series for the global and for different ocean sectors are then used to assess their consistency with ocean mass from gravimetry and total sea level from altimetry via the global sea level budget. This is done to investigate whether systematic biases can be detected in the current Argo network, to better understand the impact of Argo sampling for GOI estimations, and to quantify if deepocean changes below Argo maximum depth can be inferred via the residual global sea level budget.

This study improves our understanding of how to monitor climate-related changes and contributes to the understanding of the energy and sea level budget contributions from an Argo perspective. In Sect. 2, the data sets, methods and uncertainty estimations are described. Results for GOHC and GSSL are presented in Sect. 3, together with the sensitivity check of Argo GOIs to systematic biases and Argo sampling via the global sea level budget, as well as for regional ocean areas. Our findings are discussed in Sect. 4.

\section{Data and method}

\subsection{The ocean temperature/salinity network Argo}

The GOHC and GSSL time series are evaluated using a weighted box averaging scheme from Argo data as described in von Schuckmann and Le Traon (2011). Heat content and sea level rise are integrated between $10 \mathrm{~m}$ depth and $1500 \mathrm{~m}$ depth. The depth of $1500 \mathrm{~m}$ has been chosen as the best compromise between maximizing the number of profiles and considering the deepest layer possible (number of profiles with data in the range of 1500-2000 m dramatically drops before the year 2009; e.g., Cabanes et al., 2013, their Fig. 7). Argo data have undergone a careful quality control that includes comparison of profiles from individual floats to optimal estimation of profiles using the entire Argo data set (e.g., Gaillard et al., 2009; von Schuckmann et al., 2009).

Profiles and platforms known to have problems (mainly with pressure sensors) are excluded from the data set. Every profile "on alert" (i.e., detected as dubious by the delayed mode procedure) has been checked visually, which allows excluding spurious data (e.g., data drift). This procedure minimizes systematic biases in the global Argo data set as discussed by Barker et al. (2011). Uncertainties represent one standard error, accounting for reduced degrees of freedom in the mapping and uncertainty in the reference climatology as described in von Schuckmann and Le Traon (2011).

We have also used monthly gridded fields of temperature and salinity properties of the upper $2000 \mathrm{~m}$ over the period 2005-2012 (D2CA1S2 re-analysis). These fields were obtained by optimal analysis of the large in situ data set provided by the Argo array and complementary measurements from drifting buoys, CTDs and moorings from the CORIOLIS data center (www.coriolis.eu. org). These data have undergone the same thorough quality control procedure as described above. In total, 
the Argo measurements account for more than $95 \%$ of data used in the optimal analysis since 2005. More detailed information on this data product (and data access) can be found at http://wwz.ifremer.fr/lpo/SO-Argo/Products/ Global-Ocean-T-S/Monthly-fields-2004-2010, and in von Schuckmann et al. (2009).

\subsection{The gravimeter GRACE}

Variations in the mass component of sea level are computed using observations from the Gravity Recovery and Climate Experiment (GRACE). We use the most recent Release_05 data processed by the University of Texas Center for Space Research (Bettadpur, 2012), modified to correct deficiencies in the geocenter and $\mathrm{C}_{2.0}$ coefficient as described by Chambers and Schröter (2011). The average bottom pressure (in terms of equivalent sea level) over specific regions is computed for each month using the averaging kernel method (Swenson and Wahr, 2002). The quality of Argo coverage and the quality of altimetry product fall off rapidly poleward of $\pm 60^{\circ}$ latitude. We therefore limit our study to $\pm 60^{\circ}$ latitude and consequently define GRACE data averaging kernel over this specific area of interest. Land and ocean areas within $300 \mathrm{~km}$ of land are also excluded from the averaging kernel to minimize leakage from land hydrology and ice sheets (Chambers, 2009). The actual output from the calculation is the average ocean bottom pressure for the region, which includes both the average ocean mass component and a small, but non-negligible contribution from the time-variable average atmospheric pressure over the entire ocean basin. To compute the mass component for use in the sea level budget, this pressure signal must be subtracted for each month, which we do using data from the European Center for Medium-Range Weather Forecasting (ECMWF) that is distributed with the GRACE products (Willis et al., 2008).

GRACE measurements also require a correction for glacial isostatic adjustment (GIA) that is considerably larger than that used for altimetry. Although two very different corrections exist in the literature (derived from Peltier, 2009 and Paulson et al., 2007), both are based on the same ICE5G ice history (Peltier, 2004) and on similar mantle viscosity profiles. It has recently been discovered that the GRACE GIA correction proposed in Peltier (2009) was in error, as first suggested by Chambers et al. (2010). Peltier et al. (2012) (see also, Chambers et al., 2012) have confirmed there was a mistake in their code, so that now the two corrections are consistent. It is important to note, however, that a single value for a GRACE GIA correction cannot be used, as it is dependent on the averaging kernel utilized (Chambers et al., 2010) and is also likely uncertain at the $\pm 30 \%$ level due to considerable uncertainty in past ice loading histories over North America and Antarctica, as well as uncertainty in mantle viscosities. This uncertainty is equivalent to $\pm 0.3 \mathrm{~mm} \mathrm{year}^{-1}$ of global ocean mass, and varies for regional scales $\left(30^{\circ} \mathrm{S}-30^{\circ} \mathrm{N}\right.$ : $\pm 0.4 \mathrm{~mm}_{\text {year }}{ }^{-1} ; 30^{\circ} \mathrm{N}-60^{\circ} \mathrm{N}$ : $\left.\pm 0.6 \mathrm{~mm} \mathrm{year}^{-1} ; 60^{\circ} \mathrm{S}-60^{\circ} \mathrm{N}: \pm 0.3 \mathrm{~mm} \mathrm{year}^{-1}\right)$. This uncertainty is included in the trend estimates of the presented study (by adding in as a root-sum-square, RSS), and the correction is based on convolving the Paulson et al. (2007) GIA model with the exact averaging kernel applied to the GRACE observation. We estimate monthly uncertainty from the diagonal covariance matrix, which we calculate using values distributed with the GRACE coefficients (Swenson and Wahr, 2002) and we also include error from land and ice sheets (leakage estimated from model simulation of Chambers, 2009). The standard error for a monthly mass estimate is $1.7 \mathrm{~mm}$ equivalent sea level for the average over $60^{\circ} \mathrm{S}-$ $60^{\circ} \mathrm{N}, 4 \mathrm{~mm}$ for $30^{\circ} \mathrm{S}-60^{\circ} \mathrm{S}, 3 \mathrm{~mm}$ for $30^{\circ} \mathrm{S}-30^{\circ} \mathrm{N}$, and $6 \mathrm{~mm}$ for $30^{\circ} \mathrm{N}-60^{\circ} \mathrm{N}$.

\subsection{The satellite altimeters}

Sea level anomalies are computed from the delayed-mode AVISO gridded merged data product (SSALTO/DUACS, www.aviso.oceanobs.com), based on multiple satellite altimeters. GIA affects altimetry differently than it does GRACE, being related to the rate of change of the sea floor due to GIA, not the gravity response. It therefore has a much smaller size, and has been estimated to be $0.3 \mathrm{~mm}$ year $^{-1}$ over the $60^{\circ} \mathrm{S}-60^{\circ} \mathrm{N}$ area (Peltier, 2004). The value does differ slightly for sub-regions, and has been calculated to be $0.2 \mathrm{~mm}$ year $^{-1}$ for the $30^{\circ} \mathrm{S}-30^{\circ} \mathrm{N}$ area, $0.4 \mathrm{~mm}_{\text {year }}{ }^{-1}$ for the $30^{\circ} \mathrm{N}-60^{\circ} \mathrm{N}$ area, and $0.3 \mathrm{~mm}^{\circ} \mathrm{yr}^{-1}$ for $30^{\circ} \mathrm{S}-$ $60^{\circ} \mathrm{S}$, all based on the ICE5G-VM2 model provided by Peltier (2004). These trends are applied to each regional average (by adding), and are also assumed to have an uncertainty of $30 \%$. The uncertainty on the trend estimated from altimetry is inflated by $\pm 0.4 \mathrm{~mm}_{\text {year }}{ }^{-1}$ for every region to account for uncertainty in the drift determination of the altimeter and important corrections like the water vapor radiometer (Ablain et al., 2009; Meyssignac and Cazenave, 2012), as well as the uncertainty in GIA correction.

\subsection{The global sea level budget}

Global sea level change $\mathrm{SL}_{\mathrm{TOTAL}}$ is related to global steric

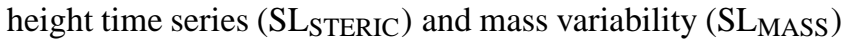
through

$\mathrm{SL}_{\mathrm{TOTAL}}=\mathrm{SL}_{\mathrm{MASS}}+\mathrm{SL}_{\mathrm{STERIC}}+\mathrm{SL}_{\mathrm{RES}}$,

where SL represents sea level (e.g., Willis et al., 2008; Leuliette and Miller, 2009). The residual of the sea level budget $\left(\mathrm{SL}_{\mathrm{RES}}\right)$ includes deep-ocean steric changes below $1500 \mathrm{~m}$ depth (i.e., depth range deeper than what we consider in our analysis of Argo), plus any source of uncertainty in observations and/or data treatment. In this section, we present results averaged for the entire region extending from $60^{\circ} \mathrm{S}$ to $60^{\circ} \mathrm{N}$, which we will, hereafter, refer to as the global ocean estimate. 
We seek to estimate the residual, $\mathrm{SL}_{\mathrm{RES}}$, using three major global observing systems: SL TOTAL is computed from altimetry products (Sect. 2.3), SLMASS from satellite gravimetry (Sect. 2.2), and SLSTERIC in the upper $1500 \mathrm{~m}$ from temperature and salinity observations from Argo (Sect. 2.1). Beside a signature of deep-ocean change, other information can be drawn from the intercomparison of these three global ocean observing systems. For instance, $\mathrm{SL}_{\mathrm{RES}}$ can also be produced by systematic observation biases, data processing uncertainties, sampling array issues, etc.

The error bar of SLRES is derived from the residual sum of squares of the errors of the three time series, assuming that they are independent. This is not exactly true, as the GIA corrections for altimetry and GRACE are derived from the same ice history (see Sects. 2.2 and 2.3), but the way the correction is applied is quite different. We account for this by increasing the trend error from the fit with the uncertainty in GIA as described in Sect. 2.2. Trends of SLRES are calculated using a weighted least square fit, taking into account the error bar of the time series as described in the appendix of von Schuckmann and Le Traon (2011). Unless otherwise stated, the error bars reflect one standard error and account for (i) the standard error in the fit, (ii) the GIA error from GRACE, and (iii) the drift error for altimetry.

\section{Results}

\subsection{Global ocean heat content and steric sea level from Argo}

The Argo-based time series of GOHC and GSSL increase from 2005 to 2012 with mean rates of $0.5 \pm 0.1 \mathrm{~W} \mathrm{~m}^{-2}$ and $0.5 \pm 0.1 \mathrm{~mm}^{-1} \mathrm{year}^{-1}$ (area of the world ocean between $60^{\circ} \mathrm{S}$ and $60^{\circ} \mathrm{N}$, and the $10-1500 \mathrm{~m}$ depth layer, Fig. 1). The trend of Argo GOHC is unchanged from the 6-year period (2005-2010) estimated by von Schuckmann and Le Traon (2011) $\left(0.5 \pm 0.1 \mathrm{~W} \mathrm{~m}^{-2}\right)$. For GSSL, the 8-year trend is $30 \%$ smaller than the previously computed 6-year trend $\left(0.75 \pm 0.2 \mathrm{mmyear}^{-1}\right)$ of von Schuckmann and Le Traon (2011), however the two trends are consistent within their uncertainty. The difference between the 6 and 8-year trends in GSSL is likely due to the strong interannual signature of El Niño-Southern Oscillation (ENSO) variability in the tropical Pacific during the end of 2010 and beginning of 2011 (Fig. 1b) which is known to strongly affect trend estimates for periods less than about 15 years (e.g., Nerem et al., 1999).

A similar signature of ENSO is observed in global mean sea level from satellite altimetry. The sea level during the period of satellite observations (1993-2012) increased at an average rate of $3.2 \pm 0.5 \mathrm{~mm} \mathrm{year}^{-1}$ (Meyssignac and Cazenave, 2012), but shows a slower rate during the Argo era from 2005 to 2010 of $2.0 \pm 0.5 \mathrm{~mm}$ year $^{-1}$ (e.g., Hansen et al., 2011). Based on the existing correlation between global
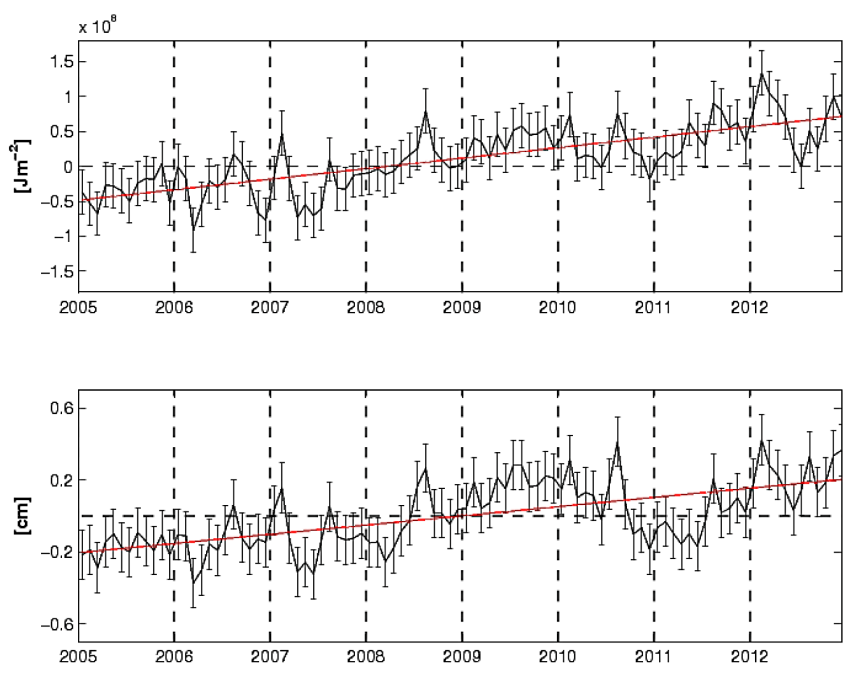

Figure 1. Global ocean $\left(60^{\circ} \mathrm{S}-60^{\circ} \mathrm{N}\right)$ heat content (upper, GOHC) and steric sea level (lower, GSSL) during the period 2005-2012 from Argo according to the method of von Schuckmann and Le Traon (2011). The 8-year trends (red line) of GOHC/GSSL account for $0.5 \pm 0.1 \mathrm{~W} \mathrm{~m}^{-2}$, and $0.5 \pm 0.1 \mathrm{~mm}$ year $^{-1}$ for the $10-1500 \mathrm{~m}$ depth layer, respectively. Error bars include data processing and climatology uncertainties, but not systematic errors.

sea level and ENSO (Nerem et al., 2010), it has been suggested that the recent slower rate of sea level rise may in part be due to the strong La Niña event in 2010/2011. One characteristic of ENSO variability is its associated vertical redistribution of heat: warmer surface layers lose heat to the deep ocean during the El Niño (warm) phase, but gain heat during La Niña (cold) events (Roemmich and Gilson, 2011). Indeed, the 2010/2011 La Niña event does show up as negative anomaly in the GOHC time series (Fig. 1a).

Interestingly, the signature of ENSO appears to be stronger in the GSSL time series than in the heat content (e.g., La Nina in 2010/2011; Fig. 1b). ENSO events are associated with an anomalous storage of water on continents during La Niña, which is related to precipitation changes (Fasullo et al., 2013) and causes a large drop in the ocean mass (Llovel et al., 2011; Cazenave et al., 2012; Böning et al., 2012). Consequently, it has been found that the slower rate of sea level rise during the period 2005-2010 can only be reconciled with steric height variability computed from Argo data if salinity effects are included to ocean mass changes (Llovel et al., 2011). Recent updated time series of global mean sea level show that the 2005-2010 slowdown was only temporary and that global sea level has recovered a mean rise of $3.2 \pm 0.5 \mathrm{~mm} \mathrm{year}^{-1}$ from the start of altimeter time series to mid-2013 (www.aviso.oceanobs.com/en/ news/ocean-indicators/mean-sea-level/ and www.columbia. edu/ mhs119/SeaLevel/). 

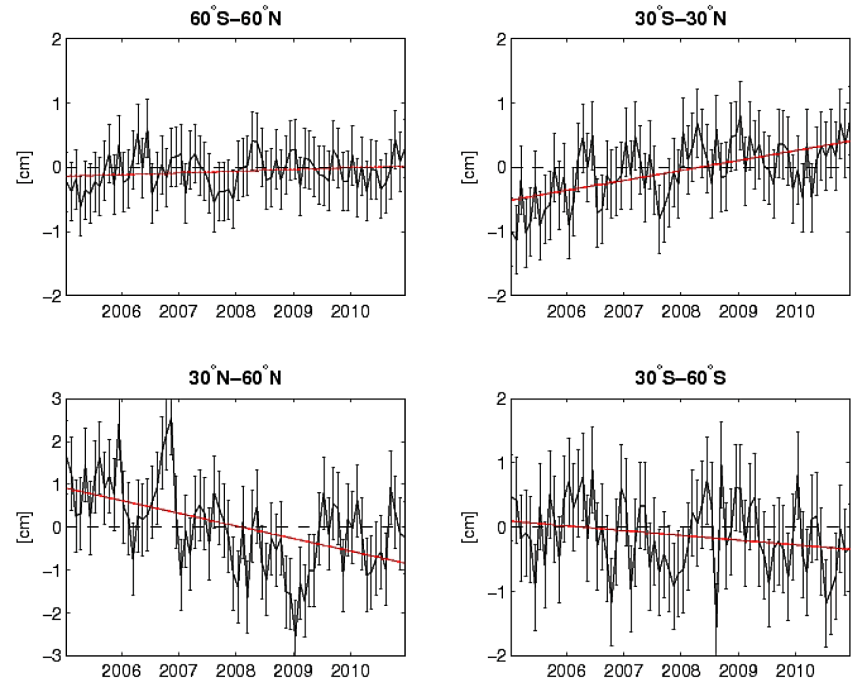

Figure 2. Residual of the sea level budget at different latitude bands using Argo steric sea level (Fig. 3a, red), AVISO delayedmode gridded fields and GRACE data. Residual trends amount to $0.3 \pm 0.6 \mathrm{~mm}_{\text {years }}{ }^{-1}$ for the global ocean, $1.6 \pm 0.7$ mm years $^{-1}$ for the Tropical Ocean, $-3 \pm 0.9$ for the Northern Ocean, and $-0.7 \pm 0.7$ for the Southern Ocean. See text for more details on data, method and error estimation.

\subsection{Observed biases in $\mathrm{SL}_{\mathbf{R E S}}$}

We now assess the coherence of the three observing systems via the sea level budget (Eq. 1) for the global ocean $\left(60^{\circ} \mathrm{S}-60^{\circ} \mathrm{N}\right)$ as well as three sectors of the world oceans: the Northern Ocean (NO) defined as $30^{\circ} \mathrm{N}$ to $60^{\circ} \mathrm{N}$, the Tropical Ocean (TO) from $30^{\circ} \mathrm{S}$ to $30^{\circ} \mathrm{N}$ and the Southern Ocean (SO) from $30^{\circ} \mathrm{S}$ to $60^{\circ} \mathrm{S}$. This regional partition differs from previous works where a more classical separation in three major ocean basins (Atlantic, Pacific and Indian) is often used. We believe that the geometry used here allows us to distinguish between regions where different processes are at work: the NO is connected to the highest latitudes in the Atlantic with significant water mass exchanges with the Arctic and from Greenland ice melt (Schmitz and McCartney, 1993; Ganachaud and Wunsch, 2000); the TO is known to have faster dynamics and climate signals related to El Niño, La Niña, and the Indian Ocean Dipole (Wang et al., 201; Saji et al., 1999; Servain et al., 1999); and the SO is the only basin with a continuous and deep current associated to intense zonally banded atmospheric forcing, is subject to significant ice melt from Antarctica, and has the largest deep warming signal observed over the last decade (Rintoul et al., 2001; Speer et al., 2000; Sallée et al., 2008; Purkey and Johnson, 2010).

The global residual SLRES shows a slight and nonsignificant positive trend of $0.3 \pm 0.6 \mathrm{~mm}$ year $^{-1}$ (Fig. 2a). In the TO sector between $30^{\circ} \mathrm{S}$ and $30^{\circ} \mathrm{N}$, the regional sea level budget has a significant positive trend of $1.6 \pm 0.7 \mathrm{~mm}$ year $^{-1}$ (Fig. 2b). In the NO sector, the residual of the regional sea level budget has a significant negative trend of $-3 \pm 0.9 \mathrm{~mm} \mathrm{year}^{-1}$ (Fig. 2c), which makes it the region of the largest residual trend. The SO shows a residual trend of $-0.7 \pm 0.7 \mathrm{~mm}$ year $^{-1}$ (Fig. 2d). These results show that although the global sea level budget over $60^{\circ} \mathrm{S}-$ $60^{\circ} \mathrm{N}$ can be closed within error bars for the years 2005 2010 , there must be systematic errors in one or all of the three observing systems in the TO or NO sectors that cancel out in the global average. Counterbalancing deep-ocean contributions that would cancel out on the global picture could potentially create these large regional residuals. However, based on the observations of Purkey and Johnson (2010), we believe the residuals in individual sectors are too high to be explained by deep-ocean change. In addition, the residual in the Southern Ocean area is of the opposite sign of what Purkey and Johnson (2010) have observed (note that residual trend in the Southern Ocean is not statistically different than zero and may reflect interannual variability and sampling errors). Thus, the attempt to close the sea level budget on smaller scales hints to unresolved systematic errors in one or more of the observing systems that are not obvious in the global integral, and that need to be considered before residuals are used to look for deep warming variations.

\subsection{Argo sampling issues}

Argo has significantly coarser resolution in both, time and space than the satellite systems (especially multi-satellite altimetry) and can therefore alias high-frequency regional signals and be more affected by mesoscale eddies. The inconsistency between Argo sampling and sampling from satellitederived products (altimetry and gravimetry) could induce a systematic drift in SLRES as observed in Fig. 2. To test the sensitivity of GOIs to this sampling issue, we subsample altimeter data on position and time of Argo profiles. Global mean SLTOTAL is then recomputed following the procedure of von Schuckmann and Le Traon (2011). The residual trend derived using the subsampled altimeter data is referred to as $\left[\mathrm{SL}_{\mathrm{RES}}\right]_{\text {sub }}$ hereinafter.

For the global ocean, the residual trend of $\left[\mathrm{SL}_{\mathrm{RES}}\right]_{\mathrm{sub}}$ changes sign, but the magnitude is still within the calculated standard error $\left(-0.6 \pm 0.6 \mathrm{~mm}\right.$ year $^{-1}$, Fig. 3a). We can therefore observe an effect of Argo sampling on global $\mathrm{SL}_{\mathrm{RES}}$, but it is small enough to remain within error bars.

Sampling errors in extra tropical areas (NO and $\mathrm{SO}$ ) are large, but do not fully explain the biases observed in Fig. 1. In the SO, the residual trend actually increases $\left(-1.5 \pm 0.7 \mathrm{~mm}\right.$ year $\left.^{-1}\right)$ when using consistent sampling for altimetry and Argo (Fig. 3d). In the NO area, the negative residual trend in the NO sector remains significant even when correcting for sampling inconsistency $\left(-2.1 \pm 0.9\right.$ mm year $^{-1}$, Fig. 3c). Nevertheless, our sampling tests, based on mapped altimetry, may still not adequately account for the true sampling of mesoscale eddies in the Kuroshio and Gulf Stream that would be seen in the Argo 

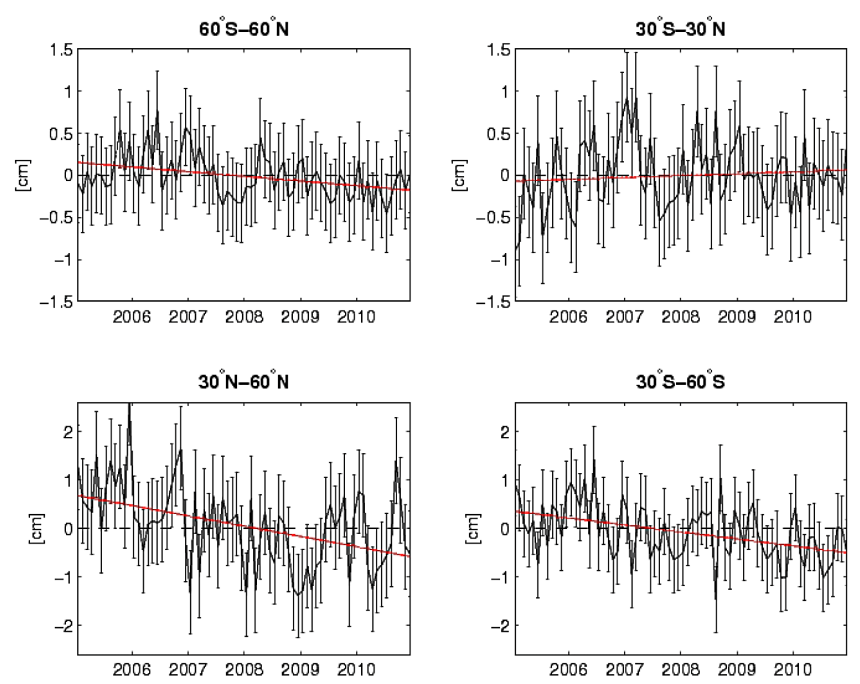

Figure 3. Same as Fig. 2, but using subsampled Altimeter data to quantify biases owing to Argo sampling (see text for more details). Residual trends amount to $-0.6 \pm 0.6$ mm years $^{-1}$ for the global ocean, $0.2 \pm 0.7 \mathrm{~mm}$ years ${ }^{-1}$ for the Tropical Ocean, $-2.1 \pm 0.9$ for the Northern Ocean, and $-1.5 \pm 0.7$ for the Southern Ocean. See text for more details on data, method and error estimation.

measurements (due to the relatively coarse resolution of satellites compared to an in situ sampling). Also, unaccounted interannual variability in Labrador Sea Water (LSW) ventilation or in other components of the North Atlantic Deep Water (e.g., Biastoch et al., 2008) could also be a factor.

Further work using high-resolution, eddy-resolving models will be needed to test whether sampling of eddies is responsible for the residual in the NO. However, we note that the area covered by the NO is less than $10 \%$ of the total area of the global ocean, so this apparent regional systematic error or sampling problem does not significantly affect the global residual analysis, accounting for only $0.3 \mathrm{~mm} \mathrm{year}^{-1}$ of the apparent global residual drift.

The largest sensitivity of SLRES to Argo sampling is observed in the TO area. When using consistent sampling for altimetry and Argo, the significant positive bias observed for $\mathrm{SL}_{\mathrm{RES}}$ (Fig. 2b) is strongly reduced for [SLRES $]_{S U B}$ $\left(0.2 \pm 0.7\right.$ mm year $^{-1}$, Fig. $\left.3 b\right)$. We can hence close the regional sea level budget for the TO area when correcting for inconsistent data sampling. But from which region is this sensitivity coming? Which areas of the TO are poorly sampled, leading to biased decadal to interannual sea level changes? In the next section we investigate the causes of such a sensitivity of sampling in the Tropical Ocean sector.

\subsubsection{The importance of the tropical Asian archipelago for the global sea level budget}

Argo floats are rarely placed in shelves and marginal seas, nor do they cover regions of seasonal and permanent ice cover. With our method for GSSL estimations (von
Schuckmann and Le Traon, 2011) we exclude all data where the bathymetry is shallower than $1000 \mathrm{~m}$ depth, which in turn eliminates the impact of marginal seas in our analysis of GSSL. In addition to these marginal seas, other regions of the world ocean are particularly difficult to observe. In particular, difficulties can arise due to political (exclusive economic zones) and security (e.g., piracy) reasons. In these regions, Argo floats are usually less deployed than in other places creating "holes" in the observing system. A clear example of such a hole created by political and security tensions is the Tropical Asian Archipelago (TAA), which represents the largest marginal sea of the TO (see green line in Fig. 4b). We define the TAA area as marginal seas bordered by the Philippines and Moluccas Islands, New Guinea in the east, North Australia in the south, the Malayan Archipelago, Thailand and Vietnam in the west, and Vietnam and China in the north. This region is thus poorly sampled by Argo, and hence, excluded from our GSSL analysis. However, the total sea level estimated from altimetry generally includes this area. In the subsampled altimeter estimation used for Fig. 3b, we excluded this region and therefore reduced the discrepancy between altimetry and Argo sampling. This is one possible explanation for the systematic error in the Tropical Ocean sector.

The horizontal distribution of sea level rise (Fig. 4a) shows large trends in the TAA region as part of a large-scale pattern spanning the area from the western tropical Pacific to the eastern tropical Indian Ocean - areas of the global ocean which are well known to be characterized by large climate variability at timescales from several years to decades (Wang et al., 2012; Saji et al., 1999). Regional steric sea level as derived from the D2CA1S2 re-analysis (see Sect. 2.1) shows high SLSTERIC trends in the western tropical Pacific, and in the eastern tropical Indian Ocean, but values close to zero in the TAA area (Fig. 4b). These values maybe due to the excessive spatial interpolation as almost no hydrographic data have been included in the D2CA1S2 re-analysis for this area (see von Schuckmann et al., 2009, their Fig. 2), as well as the fact that a simple vertical integration and mapping strategy is used. However, this is more complex than it appears. Indeed, numerous studies have shown that the steric signal seen in shallow water (such as the TAA region) is not just the integral of the local density variations integrated over the height. Shelf area regions will "see" steric fluctuations in line with deep steric signals through dynamical adjustment as explained for example by Bingham and Hughes (2012). Hence the mapping method used here is insufficient to recover the steric signal in this shallow region. What can be learned from Fig. 4b, however, is that there is a strong deep steric signal surrounding the TAA region. This suggests that the "stericinduced" signal in the TAA region is also strong and cannot be ignored in the sea level budget. 

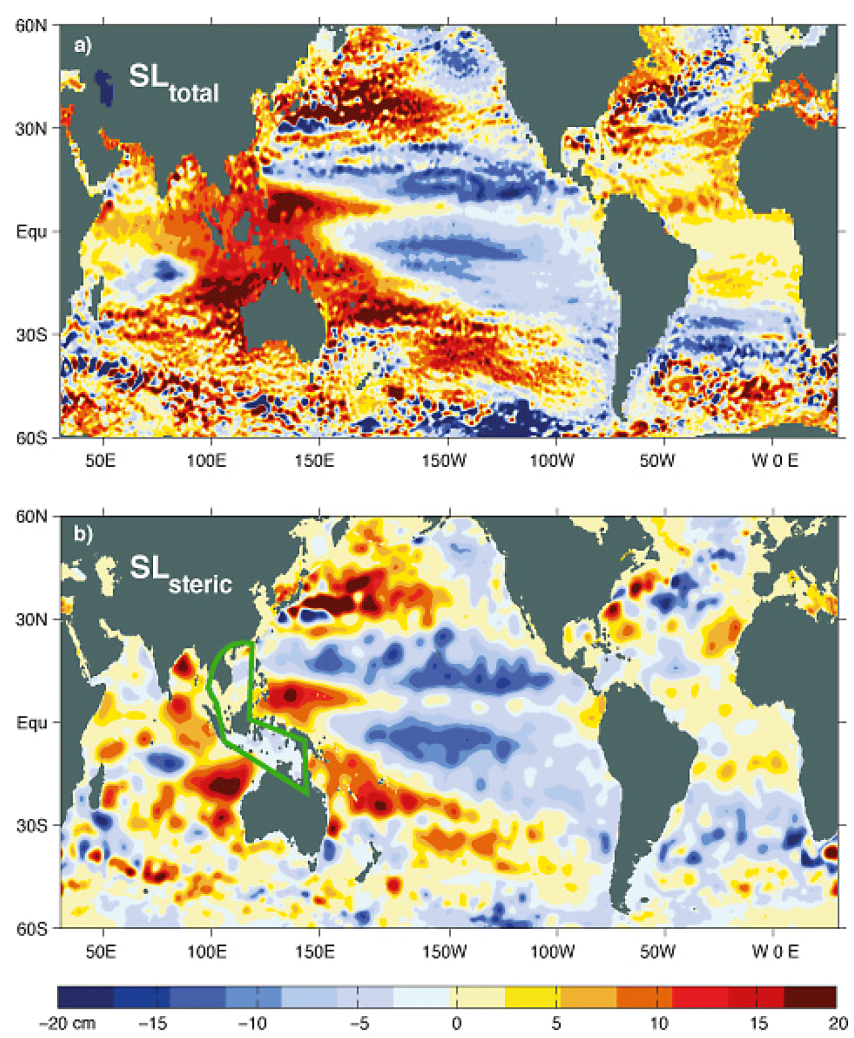

Figure 4. Map of 7-year trends (2005-2011) of (a) total sea level from AVISO and (b) steric sea level $(10-1500 \mathrm{~m})$ based on the D2CA1S2 re-analysis (see Sect. 2.1). The green bold line in (b) marks the area of the Tropical Asian Archipelago (TAA) with poor hydrographic sampling. Note that land masks are given by the different analyses (from the AVISO gridded field analysis in panel (a), and from the in situ re-analysis in panel (b), which explains the slight difference in land masks in the two panels.

Now that we have documented the cause of the regional residual in the TAA region, we seek to understand the impact of this region on the global integral of sea level. We use gridded altimeter data as a proxy to compare global sea level with and without data from the TAA region. Namely, we define a box that is representative of the TAA area where hydrographic data coverage is low (green line in Fig. 4b). We then compare the global integral of SLTOTAL (Fig. 5, black dashed line) to the global integral where SL $\mathrm{SOTAL}_{\text {data }}$ the TAA area have been ignored (red line). This experiment demonstrates the effect of poor sampling in the area of interest. Decadal-scale trends from the global integral of SLTOTAL are clearly underestimated when no data are included in the TAA area. More precisely, global total sea level rise is underestimated by $20 \%$ during the years $2005-2011$, and by $7 \%$ during the entire altimeter era 1993-2011 when no data in the TAA area are used, based on comparing trends (significant trend differences account for $0.5 \pm 0.2$ (2005-2011) and $0.2 \pm 0.05$ (1993-2011) within one standard error). Our findings show that the TAA area can have a large impact on the

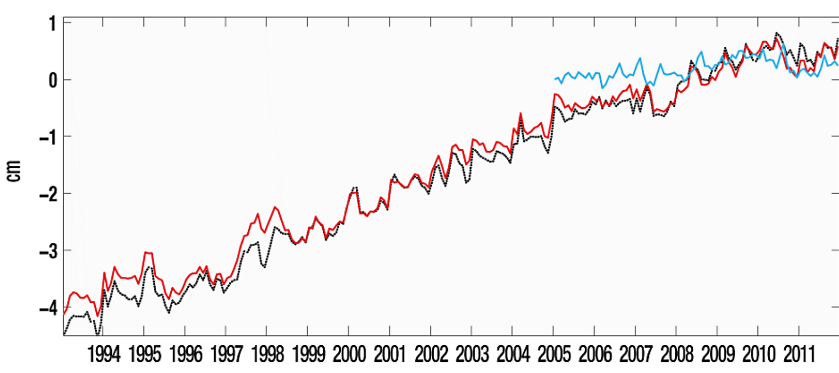

Figure 5. Global mean total (black dashed) and steric (blue, Fig. 3) sea level, together with global total sea level where data in the Tropical Asian Archipelago (TAA) have been ignored (red). The area for the TAA test (see text for more details) is added in Fig. $4 \mathrm{~b}$ (green line).

global integral, and hence, on climate change detection in the global ocean. Other very shallow parts of the World Ocean (depth less than $50 \mathrm{~m}$ ) have little impact on global rates of mean sea level for the period 1993-2011 (not shown).

\subsection{Can we indirectly infer deep-ocean changes via the global sea level budget?}

One other possible explanation for observed biases of SLRES shown in Fig. 1 would be that we might miss important deep-ocean steric changes that we ignore in our analysis. In the SO, previous studies have presented rapid and dramatic deep-ocean changes, below the depth covered by the Argo array, which would arguably cause a residual trend (e.g., Purkey and Johnson, 2010). However, these deep-ocean changes would be associated with a positive residual trend (associated with deep-ocean warming and/or freshening).

We identify a significant trend of [SLRES $]_{S U B}$ in the Southern Ocean (Fig. 3d), but this trend is negative. The negative trend is induced by a strong signature of SO interannual variability in sea level during the end of the time series (2009-2011, not shown). We note that two main mechanisms could explain these large anomalies: (i) anomalous convection events in mode and intermediate waters (e.g., Herraiz and Rintoul, 2011; Naveira-Garabato et al., 2009); or (ii) interannual variability in the $\mathrm{ACC}$ front position and associated subtropical gyre extent (e.g., Roemmich et al., 2007; Sallée et al., 2008; Sokolov and Rintoul, 2009). In addition, the year 2010-2011 was characterized by a large positive anomaly of the Southern Annular Mode, which is associated with a southward contraction and intensification of the Southern Hemisphere Subantarctic atmospheric jet (e.g., Thompson et al., 2011). A positive anomaly of this climate mode has been shown to be associated with a southward shift of ACC fronts, consistent with a positive heat content anomaly and sea level rise (Sallée et al., 2008; Sokolov and Rintoul, 2009).

The biases of SLRES and [SLRES $]_{S U B}$ are large in the NO (Figs. 2c and 3c) and also show a negative sign. In addition, previous studies have shown that abyssal thermosteric 
changes are much smaller in the North Pacific (Purkey and Johnson, 2010). Deep-ocean steric changes are therefore very unlikely to cause the observed negative residual trend in the NO. Studies in a smaller region of the North Pacific, however, find very good agreement in trends of ocean mass and steric-corrected altimetry (e.g., Chambers, 2011). The region in that study, however, was in an area with very large dynamical adjustments in ocean mass (trends of order $7 \mathrm{~mm}_{\text {year }}{ }^{-1}$ over 7 years) and away from the large mesoscale variability of the western boundary currents. Moreover, although the steric-corrected altimetry time series agreed with that of mass within the uncertainty, this was $3 \mathrm{~mm}$ year $^{-1}$ (95\% confidence), which is of the same order as the apparent systematic drift using the larger averaging area. Thus, that study would not have been able to detect this level of error in the closure of the sea level budget.

Unfortunately, we can only conclude from these experiments that uncertainties in the observing systems are too large to allow detection of deep-ocean temperature and salinity changes below $2000 \mathrm{~m}$ depth via the regional and global sea level budget.

\section{Discussion}

If we are to detect rapid climate change from GOIs using the current global observation network, it is vital to analyze and quantify uncertainties, especially systematic or correlated errors. The objective of our study was to quantify the consistency of near-global and regional integrals of ocean heat content and steric sea level (from in situ temperature and salinity data), total sea level (from satellite altimeter data) and ocean mass (from satellite gravimetry data) from an Argo perspective.

We showed that the three observing systems are consistent at global scales. Indeed, globally averaged systematic observation biases, sampling array issues and steric changes below $1500 \mathrm{~m}$ depth together are smaller than the error of SLRES. At regional scale, however, we have identified a systematic bias in some parts of the Tropical Ocean, in particular the TAA region. We also found that uncertainties in the observing systems are still too large to indirectly derive deep-ocean steric changes below $1500 \mathrm{~m}$ depth via the global sea level budget. Although the global residual budget closes within the uncertainty, this appears to be partly due to cancelation of large systematic errors. It is important to understand and correct these errors before using the analysis to detect deep warming signals.

The trends in the TAA area are sufficiently large so that ignoring this region significantly affects the Tropical Ocean steric sea level time series from Argo. The area covered by the Tropical Ocean is about $60 \%$ of the total area of the global ocean and the regional sampling issue has an important effect on the global residual analysis. This means that the TAA area is important to closing the global sea level budget on interannual to decadal timescales, which turns out to be to an important issue for climate change detection in the global ocean. In addition, we find that interannual trends can be off by as much as $20 \%$ when no data are available in the TAA area, with this error likely reduced over longer time windows.

Deep-ocean steric changes are large in the SO sector (e.g., Böning et al., 2008; Leuiliette and Miller, 2009; Sutton and Roemmich, 2011). Consistently, about half of the hemispheric total sea level rise has been found to be steric over decadal scale, with this proportion increasing southwards (Sutton and Roemmich, 2011). However, our results confirm that uncertainties in the current observing network are still too large to allow detection of deep-ocean change (deeper than $1500 \mathrm{~m}$ depth) from a global sea level budget.

Although we do not observe a significant trend in our analysis of the residual of the global sea level budget over this short period, the results will change with longer periods. If systematic errors can be fully resolved (or continue to cancel) and standard errors in the current observation networks stay constant, after 15 years we could detect a deep steric trend greater than $0.4 \mathrm{~mm} y e a r^{-1}$ at the $90 \%$ confidence level. With increasing numbers of Argo floats in the SO, and assuming continued altimetry and gravimetry, we may hope to be able to detect subtle and climatically important deep-ocean changes in the future.

However we must stress that even very good sampling in the first $2000 \mathrm{~m}$ of the ocean will never replace the need for accurate deep-ocean temperature measurements to detect subtle change and possible acceleration. This emphasizes once more the importance of deep measurements, such as from ship casts and deep Argo probes. Note that the ship casts are vital for deep Argo to work, since one cannot calibrate Argo probes with confidence without deep shipboard measurements that are carefully calibrated using IAPSO Standard Seawater and precise thermometers. Moreover, deep observations are important for estimating circulation or ventilation changes (e.g., Kouketsu et al., 2011; Purkey and Johnson, 2013).

The estimation of Argo GOIs, their related short-term trends, and the calculation of the global sea level budget in this study aims to increase the quality and confidence on global climate indicators from in situ observations. This study will contribute to preparing Argo for future monitoring of long-term climate trends of high accuracy, much needed for monitoring of the state and changes of the ocean's component of our earth's climate system.

Acknowledgements. The research leading to these results has received funding from the European Community's Seventh Framework Programme FP7/2007-2013 under grant agreement no. 283367 (MyOcean2). In addition, this work was partly funded through the French Lefe/GMMC research programme and through NASA grant NNX12AL28G for DPC. JBS received support from French ANR grant "Exciting", ANR-12-PDOC-0001, and through the British Antarctic Survey as a BAS fellow. In addition, 
comments from two anonymous reviewers greatly improved the manuscript. The authors would also like to thank Anny Cazenave, Benoit Meyssignac, Hindumathi Palanisamy and Olivier Henry for useful discussions.

Edited by: A. Sterl

\section{References}

Ablain, M., Cazenave, A., Valladeau, G., and Guinehut, S.: A new assessment of the error budget of global mean sea level rate estimated by satellite altimetry over 1993-2008, Ocean Sci., 5, 193201, doi:10.5194/os-5-193-2009, 2009.

Abraham, J. P., Baringer, M., Bindoff, N. L., Boyer, T., Cheng, L. J., Church, J. A., Conroy, J. L., Domingues, C. M., Fasullo, J. T., Gilson, J., Goni, G., Good, S. A., Gorman, J. M., Gouretski, V., Ishii, M., Johnson, G. C., Kizu, S., Lyman, J. M., Macdonald, A. M., Minkowycz,W. J., Moffitt, S. E., Palmer, M. D., Piola, A. R., Reseghetti, F., Schuckmann, K., Trenberth, K. E., Velicogna, I., and Willis, J. K.: A review of global ocean temperature observations: Implications for ocean heat content estimates and climate change, Rev. Geophys., 51, 450-483, doi:10.1002/rog.20022, 2013.

Balmaseda, M. A., Trenberth, K., and Källén, E.: Distinctive climate signals in reanalysis of global ocean heat content, Geophys. Res. Lett., 40, 1-6, doi:10.1002/grl.50382, 2013.

Barker, P. M., Dunn, J. R., Domingues, C. M., and Wijffels, S. E.: Pressure Sensor Drifts in Argo and Their Impacts, J. Atmos. Ocean. Tech., 28, 1036-1049, 2011.

Bettadpur, S.: UTCSR Level-2 Processing Standards Document for Level-2 Product Release 0005, GRACE 327-742, CSR Publ. GR12-xx, Rev 4.0, University of Texas at Austin, 16pp., 2012.

Biastoch, A., Böning, C. W., Getzlaff, J., Molines, J.-M., and Madec, G.: Causes of Interannual-Decadal Variability in the Meridional Overturning Circulation of the Midlatitude North Atlantic Ocean, J. Climate, 21, 6599-6615, 2008.

Bindoff, N. L., Willebrand, J., Artale, V., Cazenave, A., Gregory, J., Gulev, S., Hanawa, K., Le Quéré, C., Levitus, S., Nojiri, Y., Shum, C. K., Talley, L. D., and Unnikrishnan, A.: Observations: Oceanic climate change and sea level, in: Climate Change 2007: The Physical Science Basis, Contribution of Working Group 1 to the Fourth Assessment Report of the Intergovernmental Panel on Climate Change, edited by: Solomon, S., Qin, D., Manning, M., Chen, Z., Marquis, M., Averyt, K. B., Tignor, M., and Miller, H. L., chap. 5, 385-432, Cambridge Univ. Press, Cambridge, UK, 2007.

Bingham, R. J. and Hughes, C. W.: Local diagnostics to estimate density-induced sea level variations over topography and along coastlines, J. Geophys. Res., 117, C01013, doi:10.1029/2011JC007276, 2012.

Böning, C., Dispert, A., Visbeck, M., Rintoul, S. R., and Schwartzkopf, F. U.: The response of the Antarctic Circumpolar Current to recent climate change, Nat. Geosci., 1, 864-869, doi:10.1038/ngeo362, 2008.

Böning, C., Willis, J. K., Landerer, F. W., Nerem, R. S., and Fasullo, J.: The 2011 La Niña: So strong, the oceans fell, Geophys. Res. Lett., 39, L19602, doi:10.1029/2012GL053055, 2012.

Cabanes, C., Grouazel, A., von Schuckmann, K., Hamon, M., Turpin, V., Coatanoan, C., Paris, F., Guinehut, S., Boone, C.,
Ferry, N., de Boyer Montégut, C., Carval, T., Reverdin, G., Pouliquen, S., and Le Traon, P.-Y.: The CORA dataset: validation and diagnostics of in-situ ocean temperature and salinity measurements, Ocean Sci., 9, 1-18, doi:10.5194/os-9-1-2013, 2013.

Cazenave, A. and Llovel, W.: Contemporary Sea Level Rise, Ann. Rev. Marine Sci., 2, 145-173, doi:10.1146/annurev-marine120308-081105, 2010.

Cazenave, A., Henry, O., Munier, S., Delcroix, T., Gordon, A. L., Meyssignac, B., Llovel, W., Palanisamy, H., and Becker, M.: Estimating ENSO influence on the global mean sea level over 1993-2010, Mar. Geod., 35, 82-97, doi:10.1080/01490419.2012.718209, 2012.

Chambers, D. P.: Calculating trends from GRACE in the presence of large changes in ice storage and ocean mass, Geophys. J. Int., 176, 415-419, doi:10.1111/j.1365-246X.2008.04012.x, 2009.

Chambers, D. P.: ENSO-correlated fluctuations in ocean bottom pressure and wind-stress curl in the North Pacific, Ocean Sci., 7, 685-692, doi:10.5194/os-7-685-2011, 2011.

Chambers, D. and Schröter, J.: Measuring ocean mass variability from satellite gravimetry, J. Geodynam. 52, 333-343, doi:10.1016/j.jog.2011.04.004, 2011.

Chambers, D. P., Wahr, J., Tamisiea, M. E., and Nerem, R. S.: Ocean mass from GRACE and glacial isostatic adjustment, J. Geophys. Res., 115, B11415, doi:10.1029/2010JB007530, 2010.

Chambers, D. P., Wahr, J., Tamisiea, M. E., and Nerem, R.S.: Reply to comments by Peltier et al., 2012 ("Concerning the Interpretation of GRACE time dependent gravity observations and the influence upon them of rotational feedback in glacial isostatic adjustment”), J. Geophys. Res., 117, doi:10.1029/2012JB009441, 2012.

Church, J. A., White, N. J., Konikow, L. F., Domingues, C. M., Cogley, J. G., Rignot, E., Gregory, J. M., van den Broeke, M. R., Monaghan, A. J., and Velicogna, I.: Revisiting the Earth's sea-level and energy budgets from 1961 to 2008, Geophys. Res. Lett., 38, L18601, doi:10.1029/2011GL048794, 2011.

Fasullo, J. T., Boening, C., Landerer, F. W., and Nerem, R. S.: Australia's unique influence on global sea level in 2010-2011, Geophys. Res. Lett., 40, 4368-4373, doi:10.1002/grl.50834, 2013.

Gaillard, F., Autret, E., Thierry, V., Galaup, P., Coatanoan, C., and Loubrieu, T.: Quality control of large Argo data sets, J. Atmos. Oceanic Technol., 26, 337-351, 2009.

Ganachaud, A. and Wunsch, C.: Improved estimates of global ocean circulation,heat transport and mixing from hydrographic data, Nature, 408, 453-457, 2000.

Hansen, J., Sato, M., Kharecha, P., and von Schuckmann, K.: Earth's energy imbalance and implications, Atmos. Chem. Phys., 11, 13421-13449, doi:10.5194/acp-11-13421-2011, 2011.

Herraiz-Borreguero, L. and Rintoul, S. R.: Subantarctic Mode Water: distribution and circulation, Ocean Dynam., 61, 103-126, 2011.

Kouketsu, S., Doi, T., Kawano, T., Masuda, S., Sugiura, N., Sasaki, Y., Toyoda, T., Igarashi, H., Kawai, Y., Katsumata, K., Uchida, H., Fukasawa, M., and Awaji, T.: Deep ocean heat content changes estimated from observation and reanalysis product and their influence on sea level change, J. Geophys. Res., 116, C03012, doi:10.1029/2010JC006464, 2011.

Leuliette, E. W. and Miller, L.: Closing the sea level rise budget with altimetry, Argo, and GRACE, Geophys. Res. Lett., 36, L04608, doi:10.1029/2008GL036010, 2009. 
Leuliette, E. W. and Willis, J. K.: Balancing the sea level budget, Oceanography, 24, 122-129, doi:10.5670/oceanog.2011.32, 2011.

Llovel, W., Becker, M., Cazenave, A., Jevrejeva, S., Alkama, R., Decharme, B., Douville, H., Ablain, M., and Beckley, B.: Terrestrial waters and sea level variations on interannual time scale, Global Planet. Change, 75, 76-82, doi:10.1016/j.gloplacha.2010.10.008, 2011.

Loeb, G. N., Lyman, J. M., Johnson, G. C., Allan, R. P., Doelling, D. R., Wong, T., Soden, B. J., and Stephens, G. L.: Observed changes in top-of-the-atmosphere radiation and upper-ocean heating consistent within uncertainty, Nat. Geosci., 5, 110-113, doi:10.1038/NGEO1375, 2012.

Meehl, G. A., Arblaster, J. M., Fasullo, J. T., Hu, A., and Trenberth, K. E.: Model-based evidence of deep-ocean heat uptake during surface-temperature hiatus periods, Nat. Clim. Change, 1, 360364, doi:10.1038/NCLIMATE1229, 2011.

Meyssignac, B. and Cazenave, A.: Sea level: A review of presentday and recent-past changes and variability, J. Geodynam., 58, 96-109, doi:10.1016/j.jog.2012.03.005, 2012.

Naveira Garabato, A. C., Jullion, L., Stevens, D. P., Heywood, K. J. and King, B. A.: Variability of Subantarctic Mode Water and Antarctic Intermediate Water in the Drake Passage during the late-twentieth and early-twenty-first centuries, J. Climate, 22, 3661-3688, 2009.

Nerem, R. S., Chambers, D. P., Leuliette, E. W., Mitchum, G. T., and Giese, B. S.: Variations in global mean sea level associated with the 1997-1998 ENSO event: Implications for measuring long term sea level change, Geophys. Res. Lett., 26, 3005-3008, 1999.

Nerem, R. S., Chambers, D. P., Choe, C., and Mitchum, G. T.: Estimating Mean Sea Level Change from the TOPEX and Jason Altimeter Missions, Mar. Geodesy, 33, 435-446, doi:10.1080/01490419.2010.491031, 2010.

Paulson, A., Zhong, S., and Wahr, J.: Inference of mantle viscosity from GRACE and relative sea level data, Geophys. J. Int., 171, 497-508, doi:10.1111/j.1365-246X.2007.03556.x, 2007.

Palmer, M. D., McNeall, D. J., and Dunstone, N. J.: Importance of the deep ocean for estimating decadal changes in Earth's radiation balance, Geophys. Res. Lett., 38, L13707, doi:10.1029/2011GL047835, 2011.

Peltier, W. R.: Global Isostasy and the surface of the ice-age Earth: The ICE-5G (VM2) Model and GRACE, Ann. Rev. Earth Planet. Sci., 32, 111-149, doi:10.1146/annurev.earth.32.082503.144359, 2004.

Peltier, W. R.: Closure of the budget of global sea level rise over the GRACE era: The importance and magnitudes of the required corrections for global glacial isostatic adjustment, Quaternary Sci. Rev. 28, 1658-1674, doi:10.1016/j.quascirev.2009.04.004, 2009.

Peltier, W. R., Drummond, R., and Roy, K.: Comment on "Ocean mass from GRACE and glacial isostatic adjustment" by D. P. Chambers et al., J. Geophys. Res., 117, B11415, doi:10.1029/2010JB007530, 2012.

Purkey, S. G. and Johnson, G. C.: Warming of global abyssal and deep Southern Ocean between the 1990s and 2000s: contributions to global heat and sea level rise budgets, J. Climate, 23, 6336-6351, 2010.

Purkey, S. G. and Johnson, G. C.: Antarctic Bottom Water warming and freshening: Contributions to sea level rise, ocean fresh- water budgets, and global heat gain, J. Climate, 26, 6105-6122, doi:10.1175/JCLI-D-12-00834.1, 2013.

Rintoul, S., Huges, C., and Olbers, D.: The Antarctic Circumpolar Current System, Ocean Circulation and limate, edited by: Siedler, G., Church, J., and Gould, J., Academnic Press, Chap. 4.6, 271-302, 2001.

Roemmich, D. and the A. S. Team: Argo: The Challenge of Continuing 10 Years of Prog. Oceanogr., 20, 26-35, 2009.

Roemmich, D. and Gilson, J.: The 2004-2008 mean and annual cycle of temperature, salinity, and steric height in the global ocean from the Argo Program, Prog. Oceanogr., 82, 81-100, doi:10.1016/j.pocean.2009.03.004, 2009.

Roemmich, D. and Gilson, J.: The global ocean imprint of ENSO, Geophys. Res. Lett., 38, L13606, doi:10.1029/2011GL047992, 2011.

Roemmich, D., Gilson, J., Davis, R., Sutton, P., Wijffels, S., and Riser, S.: Decadal spin-up of the South Pacific subtropical gyre, J. Phys. Oceanogr., 37, 162-173, 2007.

Saji, N., Goswami, B., Vinayachandran, P., and Yamagata, T.: A dipole mode in the tropical Indian Ocean, Nature, 401, 360-363, 1999.

Sallée, J. B., Speer, K., and Morrow, R.: Southern Ocean fronts and their variability to climate modes, J. Climate, 21, 3020-3039, 2008.

Schmitz, W. and McCartney, M.: On the North Atlantic circulation, Rev. Geophys., 31, 29-49, 1993.

Servain, J., Wainer, I., McCreary, J., and Dessier, A.: Relationship between the equatorial and meridional modes of climatic variability in the tropical Atlantic, Geophys. Res. Lett., 26, 485-488, 1999.

Sokolov, S. and Rintoul, S. R.: Circumpolar structure and distribution of the Antarctic Circumpolar Current fronts: 2. Variability and relationship to sea surface height, J. Geophys. Res., 114, C11019, doi:10.1029/2008JC005248, 2009.

Speer, K., Rintoul, S. R., and Sloyan, B.: The Diabatic Deacon Cell, J. Phys. Oceanogr., 30, 3212-3222, 2000.

Sutton, P. and Roemmich, D.: Decadal steric and sea surface height changes in the Southern Hemisphere, Geophys. Res. Lett., 38, L08604, doi:10.1029/2011GL046802, 2011.

Swenson, S. and Wahr, J.: Methods for inferring regional surface-mass anomalies from GRACE measurements of time-variable gravity, J. Geophys. Res., 107, 2193, doi:10.1029/2001JB000576, 2002.

Thompson, D. W. J., Solomon, S., Kushner, P. J., England, M. H., Grise, K. M., and Karoly, D. J.: Signatures of the Antarctic ozone hole in Southern Hemisphere surface climate change, Nat. Geosci., 4, 741-749, doi:10.1038/ngeo1296, 2011.

Trenberth, K.: The ocean is warming, isn't it?, Nature, 465, 304304, 2010.

von Schuckmann, K. and Le Traon, P.-Y.: How well can we derive Global Ocean Indicators from Argo data?, Ocean Sci., 7, 783791, doi:10.5194/os-7-783-2011, 2011.

von Schuckmann, K., Gaillard, F., and Le Traon, P. Y., : Global hydrographic variability patterns during 2003-2008, J. Geophys. Res., 114, C09007, doi:10.1029/2008JC005237, 2009.

Wang, C., Deser, C., Yu, J.-Y., DiNezio, P., and Clement, A.: El Niño and Southern Oscillation (ENSO): Review. Coral Reefs of the Eastern Pacific (Springer, Berlin), 3-19, 2012. 
Willis, J. K., Chambers, D. P., and Nerem, R. S.: Assessing the globally averaged sea level budget on seasonal to interannual timescales, J. Geophys. Res., 113, C06015, doi:10.1029/2007JC004517, 2008.
Willis, J. K., Lymann, J. M., Johnson, G. C., and Gilson, J.: In situ data biases and recent ocean heat content variability, J. Atmos. Ocean. Tech., 26, 846-852, 2009. 